\title{
Groups of module automorphisms and Krull dimension and codimension
}

\author{
B. A. F. Wehrfritz ${ }^{1}$
}

Published online: 17 January 2017

(C) The Author(s) 2017. This article is published with open access at Springerlink.com

\begin{abstract}
Let $\mathrm{M}$ be a module over the ring $\mathrm{R}$ and $\mathrm{G}$ a subgroup of $\mathrm{Aut}_{\mathrm{R}} \mathrm{M}$. There has been interest of late in conditions on $R, M$ and $G$ such that one of $[M, G]$ and $M / C_{M}(G)$ small ensures that the other is also small. Here we consider when the Krull dimension (resp. codimension) of one of these bounds the Krull dimension (resp. codimension) of the other. This extends earlier work where small meant Noetherian or Artinian. Unfortunately our conclusions are patchy.
\end{abstract}

Keywords Groups of module automorphisms - Central sections of modules · Krull dimension and codimension

Mathematics Subject Classification 20C07 · 20F29 - 16D99 $\cdot 16$ P60

\section{Introduction}

Let $\mathrm{M}$ be a module over a ring $\mathrm{R}$ and $\mathrm{G}$ a subgroup of $\mathrm{Aut}_{\mathrm{R}} \mathrm{M}$. There has been interest of late in situations where one of $\mathrm{M} / \mathrm{C}_{\mathrm{M}}(\mathrm{G})$ and $[\mathrm{M}, \mathrm{G}]$ small implies the other is small. Dixon et al. [1] consider the case where $\mathrm{R}$ is a field and small means finite dimensional. Kurdachenko et al. [2] consider the case where $\mathrm{R}$ is a (commutative) integral domain and small means having a composition series of finite length. In [3] R is an arbitrary commutative ring. Here Noetherian is the main notion of small, which enables the earlier results to be recovered and extended. In [4] $\mathrm{R}$ is an arbitrary ring (with identity) all the above is set in a more general setting, enabling the above and

$凶 \quad$ B. A. F. Wehrfritz

b.a.f.wehrfritz@qmul.ac.uk

1 School of Mathematical Sciences, Queen Mary University of London, London E1 4NS, England 
more (in particular the case where small means Artinian) to be read off from just two major theorems.

The fundamental tools for [4] are the notations of Krull dimension $\kappa(\mathrm{M})$ and Krull codimension со $\kappa(\mathrm{M})$ of a module $\mathrm{M}$ (see [5] 6.2.1 and 6.1.8) and then small means having a critical composition series (shorten this to ccs; see [5] 6.2.19) or its obvious analogue of having a cocritical composition series (and shorten this to coccs; see [4]). The connection with the above is that a module $M$ is Noetherian if and only if $\operatorname{co\kappa }(\mathrm{M}) \leq 0$ and every Noetherian module has a ccs. Similarly M is Artinian if and only if $\kappa(\mathrm{M}) \leq 0$ and every Artinian module has a coccs. This suggests that the above are special cases of situations where $\alpha$ is an ordinal and small means either Krull dimension at most $\alpha$ or Krull codimension at most $\alpha$. There are some positive results in this direction but generally the situation is disappointing. A notational point: a module $M$ has no Krull dimension if and only if $M$ has no Krull codimension ([5] 6.1.8) and whenever this happens we write $\kappa(\mathrm{M})=\infty$ (or $\operatorname{co\kappa }(\mathrm{M})=\infty$ if that seems more appropriate), with $\infty$ being greater than every ordinal. The following summarizes our main positive results. Most of the work for its proof has already been done in [4]. Note that the results discussed above are all the case where $\mathrm{s}=1$, since in the notation of the theorem, $\mathrm{C}_{\mathrm{M}}(\mathrm{G})=\mathrm{Ann}_{\mathrm{M}}(\mathrm{g})$ and $[\mathrm{M}, \mathrm{G}]=\mathrm{Mg}$.

Theorem Let $R$ be a ring, $M$ a left $R$-module, $G$ a subgroup of $A u t_{\mathrm{R}} M$ and s a positive integer. Let $\mathbf{g}$ denote the augmentation ideal of $G$ in $\mathbf{Z G}$.

a) Suppose $G$ is finitely generated.

i) $\kappa\left(M / A n n_{\mathrm{M}}\left(\mathbf{g}^{\mathrm{s}}\right)\right)=\kappa\left(M \mathbf{g}^{\mathrm{s}}\right)$.

ii) $\operatorname{co\kappa }\left(M / A n n_{\mathrm{M}}\left(\mathbf{g}^{\mathrm{s}}\right)\right)=\operatorname{co\kappa }\left(M \mathbf{g}^{\mathrm{s}}\right)$.

b) Suppose $G$ has finite rank and $M \mathbf{g}^{\mathrm{s}}$ is polycritical (equivalently has a ccs).

i) $\kappa\left(M / A n n_{\mathrm{M}}\left(\mathbf{g}^{\mathrm{s}}\right)\right)=\kappa\left(M \mathbf{g}^{\mathrm{s}}\right)$.

ii) $\operatorname{co\kappa }\left(M / A n n_{\mathrm{M}}\left(\mathbf{g}^{\mathrm{s}}\right)\right) \leq \operatorname{co\kappa }\left(M \mathbf{g}^{\mathrm{s}}\right)$.

c) Suppose $G$ has finite rank and $M / A n n_{\mathrm{M}}\left(\mathbf{g}^{\mathrm{s}}\right)$ has a coccs.

i) $\kappa\left(M \mathbf{g}^{\mathrm{s}}\right) \leq \kappa\left(M / A n n_{\mathrm{M}}\left(\mathbf{g}^{\mathrm{s}}\right)\right)$.

ii) $\operatorname{co\kappa }\left(M \mathbf{g}^{\mathrm{s}}\right) \leq \operatorname{co\kappa }\left(M / A n n_{\mathrm{M}}\left(\mathbf{g}^{\mathrm{s}}\right)\right)$.

d) i) If $\kappa\left(M \mathbf{g}^{\mathrm{s}}\right)<\infty$, then $\kappa\left(M \mathbf{g}^{\mathrm{s}}\right) \leq \kappa\left(M / A n n_{\mathrm{M}}\left(\mathbf{g}^{\mathrm{s}}\right)\right)$

ii) If $\kappa\left(M / A n n_{\mathrm{M}}\left(\mathbf{g}^{\mathrm{s}}\right)\right)<\infty$ and if $R$ is the integers, then co $\kappa\left(M / A n n_{\mathrm{M}}\left(\mathbf{g}^{\mathrm{s}}\right)\right) \leq$ $\operatorname{co\kappa }\left(M \mathbf{g}^{\mathrm{s}}\right)$.

iii) If $\kappa\left(M / A n n_{\mathrm{M}}\left(\mathbf{g}^{\mathrm{S}}\right)\right)<\infty$ and if every non-zero $R$-submodule of $M \mathbf{g}^{\mathrm{s}}$ contains a non-zero projective, then co $\kappa\left(M / A n n_{\mathrm{M}}\left(\mathbf{g}^{\mathrm{s}}\right)\right) \leq \operatorname{co\kappa }\left(M \mathbf{g}^{\mathrm{s}}\right)$.

iv) If $M / A n n_{\mathrm{M}}\left(\mathbf{g}^{\mathrm{s}}\right)$ is Artinian or Noetherian, then co $\mathrm{\kappa}\left(M / A n n_{\mathrm{M}}\left(\mathbf{g}^{\mathrm{s}}\right)\right) \leq$ сок $\left(M \mathbf{g}^{\mathrm{s}}\right)$.

e) Suppose $R$ is left or right Artinian.

i) If $\kappa\left(M \mathbf{g}^{\mathrm{s}}\right)<\infty$, then

$$
\operatorname{co} \kappa\left(M \mathbf{g}^{\mathrm{s}}\right)=\kappa\left(M \mathbf{g}^{\mathrm{s}}\right) \leq \kappa\left(M / A n n_{\mathrm{M}}\left(\mathbf{g}^{\mathrm{s}}\right)\right)=\operatorname{co\kappa } \kappa\left(M / A n n_{\mathrm{M}}\left(\mathbf{g}^{\mathrm{s}}\right)\right) .
$$

ii) If $\kappa\left(M / A n n_{\mathrm{M}}\left(\mathbf{g}^{\mathrm{S}}\right)\right)<\infty$, then

$$
\operatorname{co\kappa }\left(M / A n n_{\mathrm{M}}\left(\mathbf{g}^{\mathrm{s}}\right)\right)=\kappa\left(M / A n n_{\mathrm{M}}\left(\mathbf{g}^{\mathrm{s}}\right)\right) \leq \kappa\left(M \mathbf{g}^{\mathrm{s}}\right)=\operatorname{co\kappa }\left(M \mathbf{g}^{\mathrm{s}}\right) .
$$


The main question left open by the theorem is the following. If $\operatorname{co~} \kappa\left(\mathrm{M} / \mathrm{Ann}_{\mathrm{M}}\left(\mathrm{g}^{\mathrm{s}}\right)<\right.$ $\infty$, is $\operatorname{co\kappa }\left(\mathrm{M} / \operatorname{Ann}_{\mathrm{M}}\left(\mathbf{g}^{\mathrm{s}}\right) \leq \operatorname{co\kappa }\left(\mathrm{Mg}^{\mathrm{s}}\right)\right.$ ? If so this would give a full codimension analogue to Part di). It would also imply equality in Part cii). Part di) is an easy consequence of [5] 6.2.17. This result can be restated as follows: if $\kappa(\mathrm{M})<\infty$ and if $\mathrm{M}$ is locally of Krull dimension at most $\alpha$, then $\kappa(\mathrm{M}) \leq \alpha$. The obvious codimension analogue of this, namely that if $\operatorname{co\kappa }(\mathrm{M})<\infty$ and if $\mathrm{M}$ is residually of Krull codimension at most $\alpha$, then $\operatorname{co~} \kappa \mathrm{M}) \leq \alpha$, would settle the question positively. Unfortunately this is false, even for $\mathrm{R}$ the integers; $\mathbf{Z}[1 / 2]$, for example, has Krull codimension 1, but is residually finite and hence residually of Krull codimension 0. In spite of this, for $\mathrm{R}$ the integers we do have the positive result dii). This and Parts diii), div) and e) of the theorem give partial positive answers to our question above and hence indicate where not to look for a counter example. Towards the end of this paper we give some simple examples that limit improvements to other parts of the theorem.

\section{The proofs}

We assume in this section the notation of the theorem.

Lemma $1 M$ has a ccs if and only if $M$ is polycritical.

Proof Suppose $\mathrm{N}$ is an $\mathrm{R}$-submodule of $\mathrm{M}$ with $\mathrm{N} \alpha$-critical, $\mathrm{M} / \mathrm{N} \beta$-critical and $\alpha>\beta$. Choose the submodule $\mathrm{L}$ of $\mathrm{M}$ maximal subject to $\mathrm{L} \cap \mathrm{N}=\{0\}$. The latter implies that $\kappa(\mathrm{M} / \mathrm{L})=\alpha$. If $\mathrm{L}<\mathrm{K}$, a submodule of $\mathrm{M}$, then $\mathrm{K} \cap \mathrm{N} \neq\{0\}$, so $\kappa((\mathrm{K}+\mathrm{N}) / \mathrm{K})=$ $\kappa(N /(K \cap N)<\alpha$ and hence $\kappa(M / K)<\alpha$. Therefore $M / L$ is $\alpha$-critical. If $L=\{0\}$, then $\mathrm{M}$ is $\alpha$-critical. If $\mathrm{L} \neq\{0\}$, then $\mathrm{L}$ is isomorphic to the submodule $(\mathrm{L}+\mathrm{N}) / \mathrm{N}$ of $\mathrm{M} / \mathrm{N}$ and hence $\mathrm{L}$ is $\beta$-critical. A simple induction now shows that if $\mathrm{M}$ is polycritical then $\mathrm{M}$ has a ccs. The converse is trivial.

Suppose $A_{0}$ is a subset of $\operatorname{End}_{R} M$ spanned over $\operatorname{End}_{R} M$ on both the left and the right by its subset $A$ (meaning that $A_{0} \leq A \cdot E_{R} M \cap$ End $_{R} M$.A). If $a \in A$, then $\mathrm{M} / \mathrm{Ann}_{\mathrm{M}}(\mathrm{a}) \cong$ Ma. Also $\bigcap_{\mathrm{a} \in \mathrm{A}} \operatorname{Ann}_{\mathrm{M}}(\mathrm{a})=\operatorname{Ann}_{\mathrm{M}}(\mathrm{A})=\operatorname{Ann}_{\mathrm{M}}\left(\mathrm{A}_{0}\right)$ and $\Sigma_{\mathrm{a} \in \mathrm{A}} \mathrm{Ma}=\mathrm{MA}=\mathrm{MA}_{0}$. Thus MA is an image of $\oplus_{\mathrm{a} \in \mathrm{A}}$ Ma and hence also of the direct sum of copies of $M / A n n_{M}(A)$, one copy for each a in A. Further $M / A n n_{M}(A)$ is isomorphic to a submodule of the cartesian product of copies of MA, one copy for each a in A. Thus we have the following.

Lemma 2 If $A$ is finite then

$$
\kappa\left(M / \operatorname{Ann}_{M}\left(A_{0}\right)=\kappa\left(M A_{0}\right) \text { and } \operatorname{co} \kappa\left(M / \operatorname{Ann}_{M}\left(A_{0}\right)\right)=\operatorname{co} \kappa\left(M_{0}\right)\right.
$$

Lemma 3 Let $A$ be a subset of $\operatorname{End}_{R} M$. If $\operatorname{co\kappa }\left(M / A n n_{M}(A)\right)<\infty$ and if every non-zero $R$-submodule of MA contains a non-zero projective (e.g. if $R$ is a Dedekind domain and MA is torsion-free), then

$$
\operatorname{co\kappa }\left(\mathrm{M} / \operatorname{Ann}_{\mathrm{M}}(\mathrm{A})\right) \leq \operatorname{co\kappa }(\mathrm{MA}) .
$$


Proof If a $\in \mathrm{A}$, then $\mathrm{M} / \mathrm{Ann}_{\mathrm{M}}(\mathrm{a}) \cong \mathrm{Ma}, \mathrm{MA}=\Sigma_{\mathrm{A}} \mathrm{Ma}$ and $\mathrm{Ann}_{\mathrm{M}}(\mathrm{A})=$ $\bigcap_{A} A_{M}(a)$. Suppose there exists a sequence $\left\{a_{i}\right\}$ of elements of $A$ such that if

$$
\mathrm{M}_{\mathrm{i}}=\operatorname{Ann}_{\mathrm{M}}\left(\mathrm{a}_{1}, \mathrm{a}_{2}, \ldots, \mathrm{a}_{\mathrm{i}}\right) \text {, then } \mathrm{M}>\mathrm{M}_{1}>\mathrm{M}_{2}>\cdots,>\mathrm{M}_{\mathrm{i}}>\cdots .
$$

Set $M_{*}=\bigcap_{i} M_{i}$. For each $i$ there exists a non-zero projective $P_{i}$ of $M / M_{*}$ with $\mathrm{M}_{\mathrm{i}} / \mathrm{M}_{*} \geq \mathrm{P}_{\mathrm{i}}$ and $\mathrm{P}_{\mathrm{i}} \cap\left(\mathrm{M}_{\mathrm{i}+1} / \mathrm{M}_{*}\right)=\{0\}$. Then $\mathrm{M} / \mathrm{M}_{*}$ contains $\oplus_{\mathrm{i}} \mathrm{P}_{\mathrm{i}}$ and hence $\mathrm{M} / \mathrm{M}_{*}$ does not have uniform dimension. But $\mathrm{M}_{*} \geq \operatorname{Ann}_{\mathrm{M}}(\mathrm{A})$, so $\kappa\left(\mathrm{M} / \mathrm{M}_{*}\right)<\infty$ and hence $\mathrm{M} / \mathrm{M}_{*}$ does have finite uniform dimension (see [5] 6.2.6). Therefore no such sequence $\left\{a_{i}\right\}$ exists. It follows that $A n_{M}(A)=A n_{M}(B)$ for some finite subset $\mathrm{B}$ of $\mathrm{A}$. Then $\mathrm{M} / \mathrm{Ann}_{\mathrm{M}}(\mathrm{A})$ embeds into $(\mathrm{MA})^{(\mathrm{m})}$ for $\mathrm{m}=|\mathrm{B}|$. The lemma follows.

Lemma 4 Let $R$ be a ring with nilpotent upper nil radical $\mathbf{n}$. Assume $R / \mathbf{n}$ is left or right (hence both) Artinian. If $M$ is an $R$-module then

$$
\kappa(\mathrm{M})=\operatorname{co} \kappa(\mathrm{M})=-\infty, 0 \text { or } \infty .
$$

Proof Suppose $\mathrm{M}$ is a left R-module with $\kappa(\mathrm{M})<\infty$. Now ${ }_{\mathrm{R}}(\mathrm{R} / \mathbf{n})$ is completely reducible (Artin-Wedderburn theory) and $\mathbf{n}^{\mathrm{i}-1} \mathrm{M} / \mathbf{n}^{\mathrm{i}} \mathrm{M}$ is a left $\mathrm{R} / \mathbf{n}$-module. Thus each $\mathbf{n}^{i-1} M / \mathbf{n}^{i} \mathrm{M}$ is also completely reducible. But $\kappa(M)<\infty$, so each section of $\mathbf{M}$ has finite uniform dimension. Thus each $\mathbf{n}^{\mathrm{i}-1} \mathrm{M} / \mathbf{n}^{\mathrm{i}} \mathrm{M}$ is a direct sum of finitely many irreducible left $\mathrm{R}$-modules. Therefore $\mathrm{M}$ has a composition series of finite length and hence $\kappa(\mathrm{M})=\operatorname{co\kappa }(\mathrm{M}) \leq 0$. The lemma follows.

We now prove the theorem. If $\mathrm{G}=<\mathrm{g}_{1}, \mathrm{~g}_{2}, \ldots, \mathrm{g}_{\mathrm{n}}>$, then $\mathbf{g}$ is spanned as a left and as a right $\mathbf{Z G}$-module by the $n$ elements $g_{i}-1$. Hence $\mathbf{g}^{\mathrm{s}}$ is similarly spanned by the $\mathrm{n}^{\mathrm{s}}$ products of the $\mathrm{g}_{\mathrm{i}}-1$. Thus Part a) of the theorem follows from Lemma 2. Consider Part di). Assume $\kappa\left(\mathrm{M} / \operatorname{Ann}_{\mathrm{M}}\left(\mathbf{g}^{\mathrm{s}}\right)=\alpha<\infty\right.$ and $\kappa\left(\mathbf{M g}^{\mathrm{s}}\right)<\infty$. Then $\kappa(\mathrm{Mx}) \leq \alpha$ for each $\mathrm{x}$ in $\mathbf{g}^{\mathrm{s}}$ and $\Sigma_{\mathrm{x}} \mathrm{Mx}=\mathbf{M g}^{\mathrm{s}}$. Therefore $\kappa\left(\mathrm{Mg}^{\mathrm{s}}\right) \leq \alpha$ by [5] 6.2.17. This proves Part di).

Now consider Part b). Here $\mathrm{G}$ has finite rank and $\mathrm{Mg}^{\mathrm{s}}$ is polycritical. Hence $\kappa\left(\mathrm{Mg}^{\mathrm{s}}\right)<\infty$ and therefore $\kappa\left(\mathrm{M} / \mathrm{Ann}_{\mathrm{M}}\left(\mathrm{g}^{\mathrm{s}}\right) \geq \kappa\left(\mathrm{Mg}^{\mathrm{s}}\right)\right.$. Now $\mathrm{Mg}^{\mathrm{s}}$ has a ccs by Lemma 1. Choose one such and let $\mathrm{Y}$ be the set of factors in this particular ccs. Clearly $\kappa\left(\mathrm{Mg}^{\mathrm{S}}\right)=\max \{\kappa(\mathrm{C}): \mathrm{C} \in \mathrm{Y}\}$. By Theorem 4 of [4] we have $\mathrm{M} / \operatorname{Ann}_{\mathrm{M}}\left(\mathbf{g}^{\mathrm{S}}\right) \in \mathbf{Y}_{\mathrm{R}}(\mathrm{Y})$, meaning that $\mathrm{M} / \mathrm{Ann}_{\mathrm{M}}\left(\mathbf{g}^{\mathrm{s}}\right)$ has a ccs, each factor of which is embeddable in some member of Y. Therefore $\kappa\left(\mathrm{M} / \operatorname{Ann}_{\mathrm{M}}\left(\mathbf{g}^{\mathrm{s}}\right) \leq \max \{\kappa(\mathrm{C}): \mathrm{C} \in \mathrm{Y}\}=\kappa\left(\mathrm{Mg}^{\mathrm{s}}\right)\right.$. This proves Part bi). In the same way we obtain $\operatorname{co\kappa }\left(\mathrm{M} / \mathrm{Ann}_{\mathrm{M}}\left(\mathbf{g}^{\mathrm{s}}\right) \leq \max \{\operatorname{co\kappa }(\mathrm{C}): \mathrm{C} \in\right.$ $\mathrm{Y}\}=\operatorname{co\kappa }\left(\mathbf{M g}^{\mathrm{s}}\right)$. Thus Part bii) also follows.

Now consider Part c). Here $G$ has finite rank and $M / A n_{M}\left(g^{s}\right)$ has a coccs and the proof is analogous to that of Part b). Choose a coccs of $M / A n n_{M}\left(g^{s}\right)$ and let $X$ be the set of factors in this chosen series. Then by Theorem 3 of [4] we have that $\mathbf{M g}^{\mathrm{s}} \in \mathbf{X}_{\mathrm{R}}(\mathrm{X})$, meaning that $\mathbf{M g}^{\mathrm{s}}$ has a coccs whose factors are images of elements of X.

Then

$$
\begin{aligned}
\kappa\left(\mathrm{Mg}^{\mathrm{s}}\right) & \leq \max \{\kappa(\mathrm{C}): \mathrm{C} \in \mathrm{X}\}=\kappa\left(\mathrm{M} / \operatorname{Ann}_{\mathrm{M}}\left(\mathbf{g}^{\mathrm{s}}\right)\right. \text { and } \\
\operatorname{co} \kappa\left(\mathrm{Mg}^{\mathrm{s}}\right) & \leq \max \{\operatorname{co} \kappa(\mathrm{C}): \mathrm{C} \in \mathrm{X}\}=\operatorname{co} \kappa\left(\mathrm{M} / \operatorname{Ann}_{\mathrm{M}}\left(\mathbf{g}^{\mathrm{s}}\right) .\right.
\end{aligned}
$$


This completes the proof of Part c).

Now we consider Part dii), so here $\mathrm{R}$ is $\mathbf{Z}$, the ring of integers and $\mathrm{M}$ is just an abelian group. If $\operatorname{co~} \kappa(M)<\infty$, then every section of $\mathrm{M}$ has finite uniform dimension. It follows that $\operatorname{co\kappa }(\mathrm{M})<\infty$ if and only if $\mathrm{M}$ has a series $\{0\} \leq \mathrm{A} \leq \mathrm{F} \leq \mathrm{M}$, where $\mathrm{A}$ is the torsion subgroup of $\mathrm{M}, \mathrm{F} / \mathrm{A}$ is free abelian of finite rank and $\mathrm{A}$ and $\mathrm{M} / \mathrm{F}$ are direct sums of finitely many finite cyclic and Prüfer groups. In particular it follows that if $\operatorname{co} \kappa(M)<\infty$, then $\operatorname{co\kappa }(\mathrm{M}) \leq 1$.

Now suppose we have $\mathrm{G} \leq \operatorname{Aut}_{\mathrm{Z}}(\mathrm{M})$. Set $\mathrm{N}=\operatorname{Ann}_{\mathrm{M}}\left(\mathbf{g}^{\mathrm{s}}\right)$ and assume that $\alpha=$ $\operatorname{co\kappa }(\mathrm{M} / \mathrm{N})<\infty$. We claim that $\alpha \leq \operatorname{co\kappa }\left(\mathrm{Mg}^{\mathrm{S}}\right)=\beta$; that is that $\operatorname{co} \kappa\left(\mathrm{M} / \operatorname{Ann}_{\mathrm{M}}\left(\mathbf{g}^{\mathrm{s}}\right) \leq\right.$ $\operatorname{co\kappa }\left(\mathbf{M g}^{\mathrm{s}}\right)$. Now $\alpha \leq 1$, so if $\beta \geq 1$ the claim is trivial. Clearly if $\beta<0$, then $\mathbf{M g}^{\mathrm{s}}=\{0\}$, so $\mathrm{M}=\mathrm{N}$ and hence $\alpha=\beta$. Suppose that $\beta=0$. Then $\mathbf{M g}^{\mathrm{s}}$ is finitely generated. Now $M / N$ is residually a subgroup-of-Mgs . Let $T=\bigcap S$, where $S$ ranges over all subgroups of $\mathrm{M}$ with $\mathrm{N} \leq \mathrm{S} \leq \mathrm{M}$ and $\mathrm{M} / \mathrm{S}$ free abelian of finite rank. Then $\mathrm{M} / \mathrm{T}$ has finite rank and embeds into a Cartesian product of infinite cyclic groups. From a theorem of Baer and Specker (e.g. see [6] 19.2) it follows that M/T is free abelian of finite rank. Now the torsion subgroup of $\mathbf{M g}^{\mathrm{s}}$ is finite, say of order e. Then $\mathrm{T} / \mathrm{N}$ is residually finite-of-order-dividing-e, so T/N has finite exponent dividing e. By a theorem of Prüfer (e.g. [6] 17.2) T/N is a direct sum of cyclic groups. Also T/N has finite rank. Therefore $\mathrm{T} / \mathrm{N}$ is finite (with exponent dividing e). Consequently $\mathrm{M} / \mathrm{N}$ is finitely generated and therefore $\alpha \leq 0=\beta$.

Part diii) is immediate from Lemma 3. For Part div), if $M / A n_{M}\left(\mathbf{g}^{\mathrm{s}}\right)$ is Noetherian, then $\operatorname{co\kappa }\left(\mathrm{M} / \operatorname{Ann}_{\mathrm{M}}\left(\mathbf{g}^{\mathrm{s}}\right)\right) \leq 0$ and $\mathrm{M} / \operatorname{Ann}_{\mathrm{M}}\left(\mathbf{g}^{\mathrm{s}}\right)=\{0\}$ if and only if $\mathbf{M g}^{\mathrm{s}}=\{0\}$, so this case is trivial. Now assume that $\mathrm{M} / \operatorname{Ann}_{\mathrm{M}}\left(\mathbf{g}^{\mathrm{s}}\right)$ is $\operatorname{Artinian}$. Then $\operatorname{Ann}_{\mathrm{M}}\left(\mathbf{g}^{\mathrm{s}}\right)=$ $\bigcap_{\Phi} \operatorname{Ann}_{M}(\phi)$ for some finite subset $\Phi$ of $\mathbf{g}^{\mathrm{s}}$ and each $\mathrm{M} / \mathrm{Ann}_{\mathrm{M}}(\phi) \cong \mathrm{M} \phi \leq \mathbf{M g}^{\mathrm{s}}$. Therefore $\operatorname{co\kappa }\left(M / \operatorname{Ann}_{M}\left(\mathbf{g}^{\mathrm{s}}\right)\right) \leq \operatorname{co\kappa }\left(\mathbf{M g}^{\mathrm{s}}\right)$. Finally $\mathrm{M} / \operatorname{Ann}_{\mathrm{M}}\left(\mathbf{g}^{\mathrm{s}}\right)=\{0\}$ if and only if $\mathrm{Mg}^{\mathrm{s}}=\{0\}$ and a left or right Artinian ring has its upper nil radical nilpotent. Thus Part e) follows from Lemma 4. This completes the proof of the theorem.

Examples Let $\left\{\mathrm{x}_{\mathrm{i}}: \mathrm{i}=0,1,2, \ldots\right\}$ be a basis of the vector space $\mathrm{M}$ over the field R. Firstly let $N=<x_{i}: i \geq 1>$. If $G \leq A_{R} M$ is the stability group of the series $\mathrm{M}>\mathrm{N}>\{0\}$, then $\mathrm{N}=\mathrm{C}_{\mathrm{M}}(\mathrm{G})=[\mathrm{M}, \mathrm{G}], \kappa(\mathrm{M} / \mathrm{N})=0=\operatorname{co} \kappa(\mathrm{M} / \mathrm{N})$ and $\kappa(N)=\infty=\operatorname{co} \kappa(N)$. Also $M / N$ is 0 -critical and 0 -cocritical.

Secondly let $\mathrm{N}=\mathrm{Rx}_{0}$. If $\mathrm{G} \leq \mathrm{Aut}_{\mathrm{R}} \mathrm{M}$ is the stability group of the series $\mathrm{M}>$ $\mathrm{N}>\{0\}$, then $\mathrm{N}=\mathrm{C}_{\mathrm{M}}(\mathrm{G})=[\mathrm{M}, \mathrm{G}], \kappa(\mathrm{M} / \mathrm{N})=\infty=\operatorname{co\kappa }(\mathrm{M} / \mathrm{N})$ and $\kappa(\mathrm{N})=$ $0=\operatorname{co} \kappa(\mathrm{N})$. Also $\mathrm{N}$ is 0 -critical and 0 -cocritical. Thus there are no general results available without some further hypotheses as in every section of the theorem.

Now let $\mathrm{R}$ denote the integers and $\mathrm{M}=\mathrm{Q} \oplus \mathrm{N}$, where $\mathrm{Q}$ is infinite cyclic and $\mathrm{N}$ is a Prüfer group. If $G \leq$ Aut $_{R} M$ is the stability group of the series $M>N>\{0\}$, then $\mathrm{G}$ is abelian of rank 1 and $\mathrm{N}=\mathrm{C}_{\mathrm{M}}(\mathrm{G})=[\mathrm{M}, \mathrm{G}]$. Also $\kappa(\mathrm{M} / \mathrm{N})=1=\operatorname{co} \kappa(\mathrm{N})$ and $\kappa(N)=0=\operatorname{co} \kappa(M / N)$. Further $M / N$ is 1-critical, $N$ is 1 -cocritical and $\kappa(M)=1=$ $\operatorname{co\kappa }(\mathrm{M})$.

Thus in the Theorem Part bi) it is not sufficient for $\mathrm{G}$ just to have finite rank, even if $\mathrm{M} / \mathrm{Ann}_{\mathrm{M}}(\mathbf{g})$ is critical. In cii) the claim is also false without the coccs assumption, even if Mg is cocritical. Further in Part di) we need not have equality. 
Open Access This article is distributed under the terms of the Creative Commons Attribution 4.0 International License (http://creativecommons.org/licenses/by/4.0/), which permits unrestricted use, distribution, and reproduction in any medium, provided you give appropriate credit to the original author(s) and the source, provide a link to the Creative Commons license, and indicate if changes were made.

\section{References}

1. Dixon, M.R., Kurdachenko, L.A., Otal, J.: Linear analogues of theorems of Schur, Baer and Hall. Int. J. Group Theory 2, 79-89 (2013)

2. Kurdachenko, L.A., Subbotin, IYa., Chupordia, V.A.: On the relations between the central factor-module and the derived submodule in modules over group algebras. Comment. Math. Univ. Carol. 56, 433-445 (2015)

3. Wehrfritz, B.A.F.: On soluble groups of finite rank of module automorphisms, Czechoslovak Math. J. (to appear)

4. Wehrfritz, B.A.F.: Groups of module automorphisms of finite rank, Rend. Circ. Mat. Palermo (to appear). doi:10.1007/s12215-016-0252-z

5. McConnell, J.C., Robson, J.C.: Noncommutative Noetherian Rings. John Wiley and Sons, Chichester (1987)

6. Fuchs, L.: Infinite Abelian Groups, vol. 1. Academic Press, New York (1970) 